\title{
Research on The Evolution of High-tech Industry Competitiveness in Beijing-Tianjin-Hebei
}

\author{
Yanxia $\mathrm{LI}^{1 *}$, Jie Zhang ${ }^{1}$ \\ ${ }^{1}$ School of Management, Tianjin University of Technology, Tianjin, China
}

\begin{abstract}
From the perspective of ecological niche, this paper constructs the evaluation index system of the competitiveness of beijing-tianjin-hebei high-tech industry, and analyzes the competitiveness of beijingtianjin-hebei high-tech industry from the perspectives of niche value, niche width and niche overlap. The results show that :(1) from the perspective of ecological niche, the niche value of the competitiveness of hightech industries in Beijing, tianjin and hebei does not show an increasing trend with time, and the overall value of the niche is ranked from the largest to the smallest: Beijing, tianjin and hebei.(2) from the niche breadth, beijing-tianjin-hebei high-tech industry competitiveness niche breadth range as follows: 0.26-0.83, Beijing niche width of the widest, hebei niche breadth the narrowest, Beijing and tianjin hi-tech industry competitiveness niche breadth value reduced trend on the whole, hebei niche breadth on overall growth trend.
\end{abstract}

\section{Introduction}

Under the global economic situation, with the continuous advancement of scientific and technological innovation and the continuous improvement of informatization level, the competition among regions focuses on the high-tech field. As the most dynamic high-tech industry in economy, it has huge market potential. Its development can attract overseas students, improve innovation ability, increase industrial output value, drive regional development, and improve regional strength and competitiveness.Beijing, Tianjin and Hebei are located in a special area. The planning of coordinated development started late. There are many problems in the three places, such as uneven distribution of capital, human and material resources, different government support, and geographical differences. How to reduce regional differences, give full play to industrial advantages, and promote the coordinated development of Beijing, Tianjin and Hebei is worth indepth study. It is of practical significance to implement policy support and update resource allocation.

\section{Literature review}

As a whole concept, the competitiveness of high-tech industry reflects the comprehensive strength of patent application, new product development and achievement transformation of high-tech industry. Ye Qilin and Zhang Jianming used the entropy method to evaluate the competitiveness of Shanghai's high-tech industry, and concluded that the competitiveness of Shanghai's hightech industry showed an increasing trend over time, followed by the problems of industrial output and policy capacity[1]. Pan Xia and $\mathrm{Ju}$ Xiaofeng divided the competitiveness of high-tech industries into internal competitiveness and external competitiveness, and combined factor analysis and cluster analysis to rank the competitiveness of high-tech industries in some regions [2]. He Hongguang and Li Guangqin rank first based on the dynamic shift share spatial modelFrom the evaluation and comparison of six high-tech industries, such as medical and pharmaceutical equipment manufacturing industry and special equipment manufacturing industry, it is concluded that Guangdong is the most competitive high-tech industry, and Beijing Tianjin Hebei is not obvious in the competitive advantage [3].

The concept of "niche" was first proposed by Grinnell. With the development, it is defined as the position of a population in time and space in the natural ecosystem and its functional relationship with related populations [4]. Based on the theories of ecology and innovation system, Chen Honghua and Yin Ximing put forward the concept of science and technology innovation niche and summarized its competitive strategy[5].Luo Wei et al. Based on the niche perspective, explored the gap of scientific and technological innovation development in the Yangtze River economic belt, evaluated the competitiveness of scientific and technological innovation from three specific dimensions of niche, and concluded that the comprehensive niche value of Jiangsu in the Yangtze River Economic Belt ranked first, followed by Shanghai, and the niche value of Shanghai continued to decline [6].

\footnotetext{
*Corresponding author: 13753861165@163.com
} 


\section{Construction of evaluation model and index system}

\subsection{Model building}

\subsubsection{Niche situation model}

Niche situation theory is the basis of this paper to evaluate the competitiveness of high-tech industry,"State" refers to the real state of high-tech industry, which represents the resources and development basis of high-tech industry, and is the result of interaction between high-tech industry and social resources and environment"It refers to the influence and dominant power of high-tech industry, representing the development potential of high-tech industry. This paper constructs the niche situation model of high-tech industry competitiveness:

$$
N_{i}=\left(S_{i}+A_{i} T_{i}\right) / \sum_{j=1}^{n}\left(S_{j}+A_{j} T_{j}\right)
$$

\subsubsection{Niche breadth mode}

The niche breadth of high-tech industry refers to the sum of all kinds of resources used by a province (city) in the development of high-tech industry, and also represents the diversification of the characteristics of high-tech industry in the use of market resources. The improved Shannon model is used.

$$
A_{i}=-\sum_{j=1}^{R} P_{j} \lg P_{j}
$$

\subsection{Index selection}

The competitiveness of high-tech industry is the strength formed by many factors. Based on the principles of comprehensiveness, scientificalness, desirability and predictability, and referring to the evaluation index system of relevant scholars, this paper constructs a high-tech industry with four dimensions of industrial input ability, industrial output ability, industrial innovation ability and innovation support environment as the first level index. The competitiveness evaluation model is shown in Table 1.

\begin{tabular}{|c|c|}
\hline First level indicators & Secondary indicators \\
\hline \multirow{6}{*}{ Industrial input capacity } & Investment in industrial fixed assets \\
\hline & Internal expenditure of R \& D research funds \\
\hline & Expenditure on new product development \\
\hline & Expenditure on technology introduction \\
\hline & $\mathrm{R} \& \mathrm{D}$ researchers at that time \\
\hline & $\mathrm{R} \& \mathrm{D}$ investment intensity \\
\hline \multirow{2}{*}{$\begin{array}{l}\text { Industrial output } \\
\text { capacity }\end{array}$} & Market share of industrial products \\
\hline & Export delivery value \\
\hline \multirow{5}{*}{$\begin{array}{l}\text { Industrial innovation } \\
\text { capability }\end{array}$} & Sales revenue of new products \\
\hline & Number of valid invention patents \\
\hline & Number of new product development projects \\
\hline & Number of research institutions \\
\hline & Number of $\mathrm{R} \& \mathrm{D}$ projects \\
\hline \multirow{5}{*}{$\begin{array}{l}\text { Industrial support } \\
\text { environment }\end{array}$} & Total output value of national high tech Industrial Development Zone \\
\hline & Full time equivalent of R\&D personnel in Colleges and Universities \\
\hline & $\begin{array}{l}\text { The proportion of government } \mathrm{r} \& \mathrm{~d} \text { funds in the internal expenditure of } \\
\text { industrial R \& D funds }\end{array}$ \\
\hline & Proportion of R \& D internal expenditure in GDP \\
\hline & $\begin{array}{l}\text { Proportion of government science and technology appropriation in local } \\
\text { financial expenditure }\end{array}$ \\
\hline
\end{tabular}

Table 1. construction of Beijing Tianjin Hebei high tech industry competitiveness evaluation index system

\section{Results description and analysis}

\subsection{The niche value of Beijing Tianjin Hebei high tech industry competitiveness}

In order to better show the temporal changes of the competitiveness of high-tech industries in Beijing, Tianjin and Hebei, this paper takes two years as a stage, and divides the sample data from 2009 to 2017 into four stages."State" is the data of each index in 2010, 2012, 2014 and 2016 respectively, "potential" is the growth value of each index data in 2010, 2012, 2014 and 2016 respectively, and the dimensional conversion coefficient is 
1.Firstly, the niche value of each dimension of high-tech industry competitiveness of Beijing, Tianjin and Hebei in four stages is calculated by the niche situation model of equation (1), as shown in figure1.

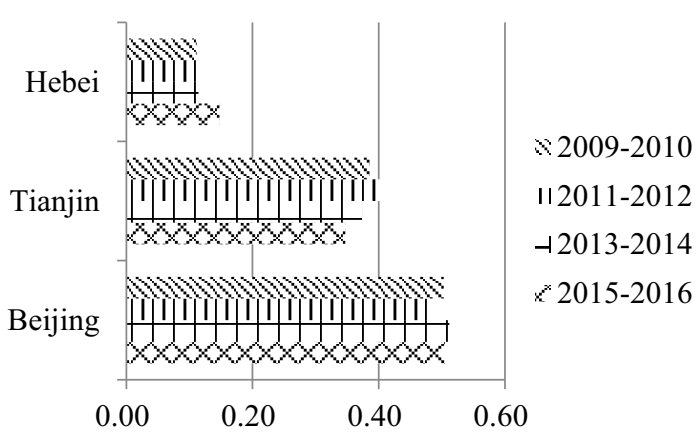

Fig 1. Niche value of Beijing Tianjin Hebei high tech industry competitiveness

The results show that: Beijing, Tianjin and Hebei hightech industry competitiveness niche value does not show an increasing trend with time.Hebei's niche value is in the range of $(0.1,0.15)$, Tianjin's niche value is in the range of $(0.34,0.41)$, and Beijing's niche value is in the range of $(0.47,0.52)$. On the whole, Beijing's competitiveness ranks first, Tianjin's is in the middle, Hebei's is behind, and Hebei has a large gap with Beijing and Tianjin.

\subsection{The niche breadth of Beijing Tianjin Hebei high tech industry competitiveness}

According to table 2, The niche breadth of high-tech industry competitiveness in Beijing, Tianjin and Hebei ranges from 0.26 to 0.83 . Among them, Beijing has the widest niche breadth and the strongest industrial competitiveness, while Hebei has the narrowest niche breadth and weak competitiveness. The niche breadth of high-tech industry competitiveness in Beijing and Tianjin showed a decreasing trend as a whole. The niche breadth of Beijing decreased by 0.04 , and that of Tianjin decreased by 0.01 . The niche breadth of Hebei showed an increasing trend as a whole.

Table 2. niche breadth of Beijing Tianjin Hebei high tech industry competitiveness

\begin{tabular}{|c|c|c|c|}
\hline Years & Beijing & Tianjin & Hebei \\
\hline 2009 & 0.80 & 0.53 & 0.28 \\
\hline 2010 & 0.77 & 0.56 & 0.30 \\
\hline 2011 & 0.83 & 0.53 & 0.27 \\
\hline 2012 & 0.79 & 0.55 & 0.29 \\
\hline 2013 & 0.80 & 0.54 & 0.29 \\
\hline 2014 & 0.78 & 0.54 & 0.32 \\
\hline 2015 & 0.72 & 0.60 & 0.32 \\
\hline 2016 & 0.75 & 0.54 & 0.36 \\
\hline 2017 & 0.76 & 0.52 & 0.37 \\
\hline
\end{tabular}

\section{Conclusion and suggestion}

According to the above research conclusions, this paper puts forward the following suggestions:

First,give full play to the role of the government to promote the sustainable development of high-tech industries in Beijing, Tianjin and Hebei.The government plays the role of financial support and policy incentives in the development of high-tech industries in Beijing, Tianjin and Hebei. According to the actual development situation of Beijing, Tianjin and Hebei, the government should formulate different development policies according to local conditions, and increase the support for the development of high-tech industries in terms of talents, technology and funds.

Sceond,seize the opportunity to continuously improve the competitiveness of high-tech industry in Hebei
Province. Hebei Province has less investment in R\&D researchers and R\&D research funds, low level of innovation in the number of effective invention patents and new product sales revenue, and has a lot of room to improve the competitiveness of high-tech industry.

\section{Acknowledgments}

This work was financially supported by Tianjin postgraduate research innovation program fund.(No. 2020YJSS030)

\section{References}

1. Ye Qilin, Zhang Jianming. Competitiveness evaluation of high tech industry in Shanghai [J]. Science and technology management research, 40,2(2020). 
2. Pan Xia, Ju Xiaofeng, Chen Jun. research on the competitiveness evaluation of high tech industry in 29 regions of China based on factor analysis [J]. Exploration of economic problems, 4,(2013)

3. He Hongguang, Li Guangqin, Xie Yazhu. A comparative study on the competitiveness of high tech industries in China's coastal areas -- Based on the dynamic shift share space model $[\mathrm{J}]$. Science and technology management research,35,22(2015)

4. Grinnell J . The Niche - Relationships of the California Thrasher [J]. Auk,34,7(1917)

5. Chen Honghua, Yin Ximing, Chen Jin, Wang Luyao. Research on science and technology innovation niche based on integrated innovation theory [J]. Science of science and technology management, 40 ,5(2017)

6. Yang xuanzhi, Luo Wei, Tang Zhen. Evaluation and evolution of science and technology innovation competitiveness of Yangtze River economic belt from the perspective of niche [J]. Soft science,33,7(2019) 